
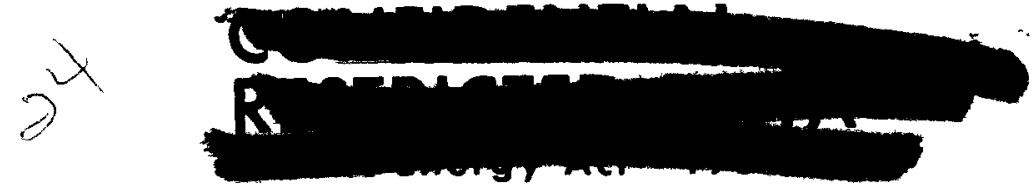

DECEMBER 22, 1964

W ANL-TME-1068

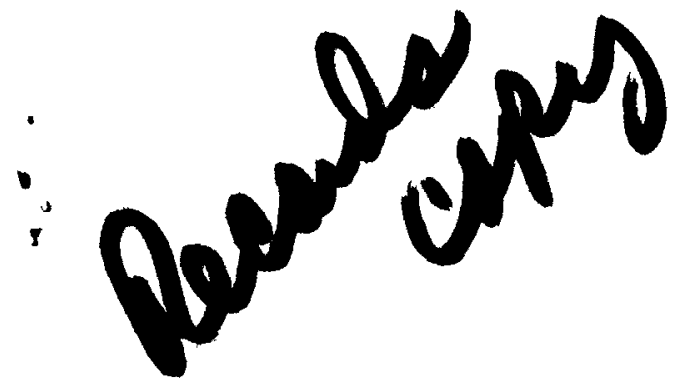

NOTICE

This report was prepared as an account of sponsored by the United States Government. Nt the United States nor the United States Energy Research and Development Administration, nor any of their employees, nor any of their contractors, subcontractors, or their employees, makes any warranty, express or implied, or assumes any legal liability or responsibility for the accuracy, completeness or usefulness of any information, apparatus, product or process disclosed, or represents that its use would not infringe privately owned rights.

\title{
MASTER
}

\section{REACTOR DESIGN AND DEVELOPMENT PROGRAM}
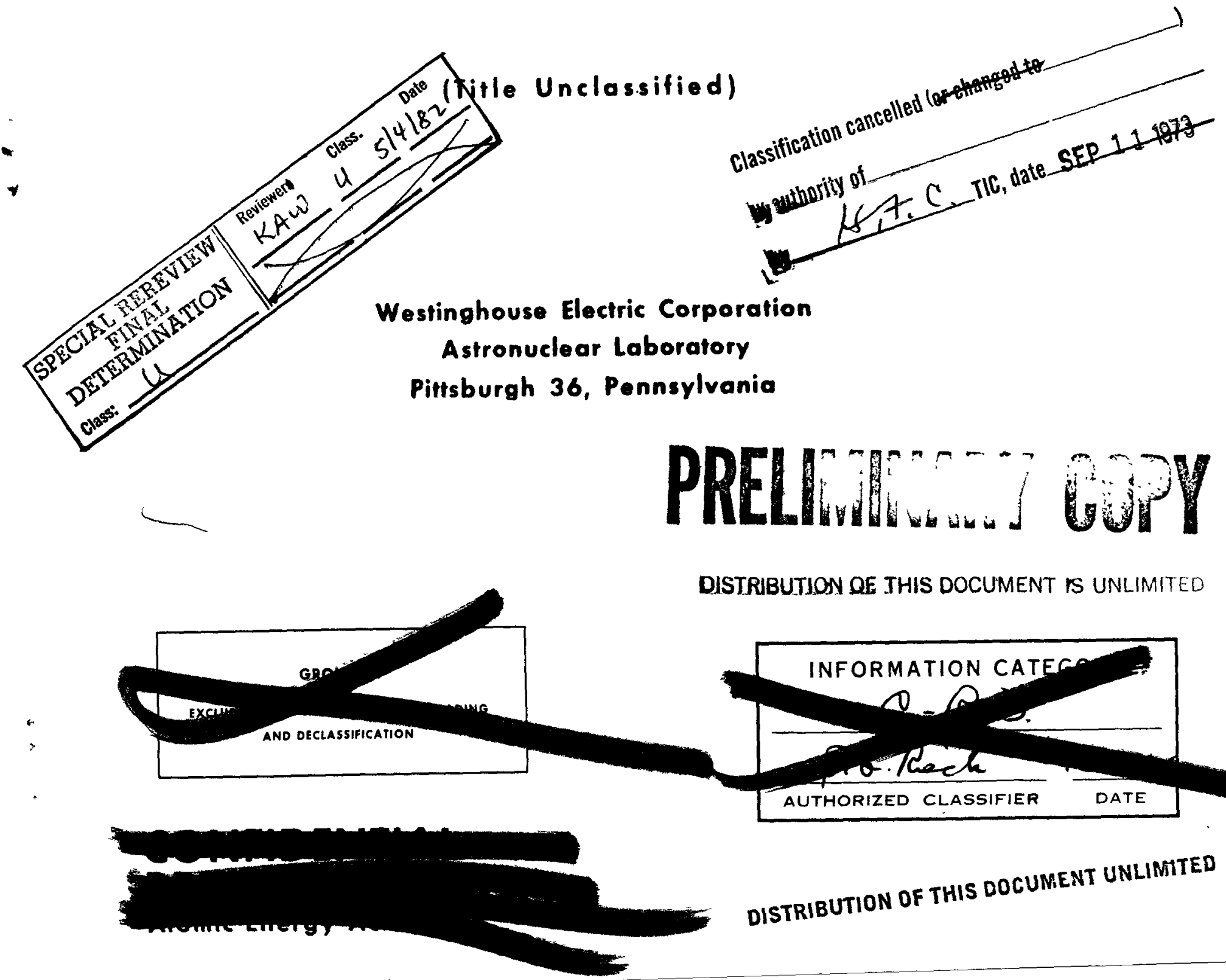

DISTRIBUTION OE THIS DOCUMENT IS UNLIMITED

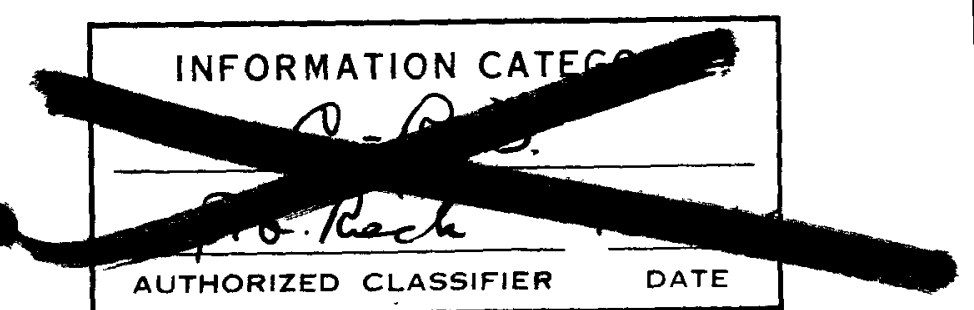




\section{DISCLAIMER}

This report was prepared as an account of work sponsored by an agency of the United States Government. Neither the United States Government nor any agency Thereof, nor any of their employees, makes any warranty, express or implied, or assumes any legal liability or responsibility for the accuracy, completeness, or usefulness of any information, apparatus, product, or process disclosed, or represents that its use would not infringe privately owned rights. Reference herein to any specific commercial product, process, or service by trade name, trademark, manufacturer, or otherwise does not necessarily constitute or imply its endorsement, recommendation, or favoring by the United States Government or any agency thereof. The views and opinions of authors expressed herein do not necessarily state or reflect those of the United States Government or any agency thereof. 


\section{DISCLAIMER}

Portions of this document may be illegible in electronic image products. Images are produced from the best available original document. 


\section{REACTOR DESIGN AND DEVELOPMENT PROGRAM FOR REACTORS A-7 THROUGH A-10}

\section{DEFINITION OF PROBLEMS IN NRX-A:}

The hot tests on the KIWI reactors and on the NRX-A2 together with the component tests have identified the major areas requiring substantially design improvements in the NRX-A2 reactor in order to achieve a reactor capable of operating at one hour or more full power.

This memorandum will discuss primarily the required design and analysis effort. This effort must be supported by an adequate component test program. A parallel development program is required to produce an improved fuel to select and demonstrate the capability of non-fuel materials to develop a reactor control system and to develop adequate in-core instrumentation.

Corrosion effects in the peripheral and interstitial core regions, the support blockfuel element interfaces, and in-core instrumentation central element corrosion are identified as the major problem areas in NRX requiring substantial improvement to obtain a reliable reactor capable of operating for more than one hour. Additional problems probably will be identified by future reactor runs and component tests. However, it is felt the above are the major problems.

There are other design changes which would improve the reactor or reduce its cost, but not necessarily increase its lifetime. For example: the interfaces between the reactor, pressure vessel and nozzle should be simplified. The reactor should be designed so that disassembly after a hot run is simplified. It would be desirable to re-use major components. 


\section{DEVELOPMENT PROGRAM:}

Over the past year there has been considerable thought given to possible design approaches which solve the identified problems. The attached sketches illustrate some of the ideas which have developed in this preliminary examination.

Core Periphery:

There are several functions which must be performed in the core peripheral area: First, it must provide a thermal insulation between the hot core and the cold reflector system. Second, it must provide the forces required to keep the core bundled together and to counteract the accelerating forces expected during operations. Third, it must prevent excessive leakage of hydrogen through this region to the exhaust plenum. Superimposed on these, the corrosion of the hot fuel elements or other parts must be limited to a tolerable level.

Westinghouse proposes to attack these problems in the following ways:

A. Reduce the hydrogen availability at the core periphery by bathing this region with hot nearly stagnent hydrogen rather than cold flowing hydrogen. To achieve this, it is necessary to entirely eliminate pin leakage. In addition the axial leakage must be reduced to an absolute minimum by eliminating the cooling requirements for seal segments and filler strips. It is estimated the axial flow through a tight periphery of this kind would be as low as $1.8 \mathrm{lb} / \mathrm{hr}$ based on tests of seals for the NRX-A design. At this rate of flow, the graphite loss might be $1.2 \mathrm{lb} / \mathrm{hr}$. 
B. Move the critical corrosion area away from the core surface. By eliminating the cooling of the filler strips and seal segments, these parts would operate at temperatures somewhat above the adjacent fuel surface; therefore, the critical corrosion area would be moved away from the peripheral fuel element surface. The filler strip seal segments area would be designed so that the temperature profile resulted in corrosion occuring on the non-critical surfaces.

C. Reduce the corrosive characteristics of the stagnent peripheral gas by additives:

1. Hydro-carbons, such as methane, have been suggested as additives. This type of additive would probably reduce corrosion, but not prevent it, as there would be re-deposition of pyro graphite in the relatively cooler regions and some corrosion of hotter graphite. Freezing of a hydro-carbon during start-up would be a problem.

2. Since the amount of gas flowing through the peripheral region would be drastically reduced, helium could be considered as a replacement for the hydrogen in this region. The amount of helium required would not be excessive and a simple system for this addition could be devised.

3. Because the filler strips and seal segments are uncooled, they would operate at temperatures above the fuel element surface. This would move the corrosion area away from the fuel element surfaces. In addition sacrificial graphite designed to operate at temperatures higher than the fuel elements, filler strips or seal segments can be added to provide hydro-carbons to protect the critical surface from corrosion.

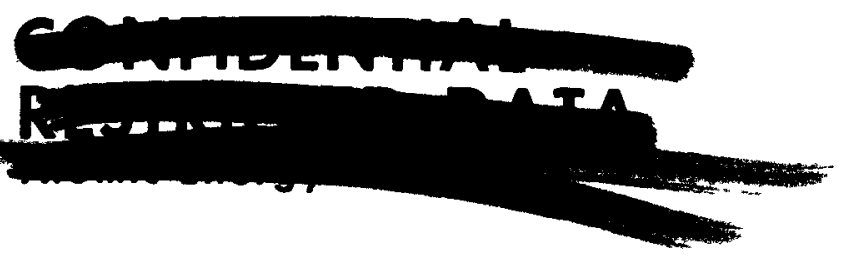




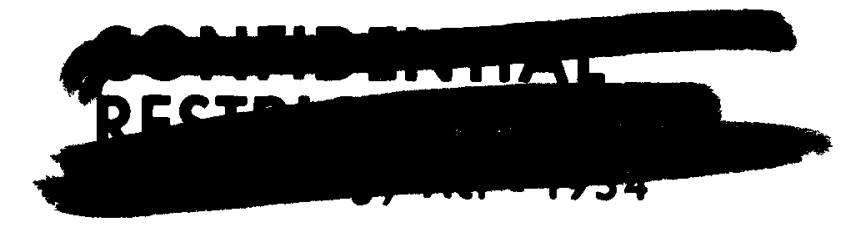

D. Data on the effectiveness of coated peripheral fuel elements will be obtained in the NRX-A3 run. This data would be factored into the design of the peripheral area.

Core Interstitial Corrosion:

The interstitial corrosion problems are somewhat different than the peripheral corrosion problems of the reactor in that the temperatures approach isothermal conditions locally. Therefore, providing means of permitting the high temperature differences between parts are not required. The interstitial corrosion can be reduced to a low value by making sure that the fuel elements and the central non-fuel elements fit tightly together to reduce the interstitial flow. This tight fit-up requirement imposed two demands on the design. First, all of the parts must have small dimensional variations and, second, the bundling forces on the core must be high.

Leakage of interstitial hydrogen gas into the core at the cold end can be substantially reduced by a tight core band and possibly cementing the fuel elements and clusters together at this end. However ${ }_{8}$ this approach must be examined in some detail because it can cause new problems. If it is carried to extremes, it will result in a substantial reduction of the interstitial pressure down stream. The KIWI tests showed that if the interstitial pressure drops below the bore pressure, there can result substantial corrosion due to leakage of propellant from the bores through cracks and pin holes in the bore cladding then through the fuel element to the interstitial area. In some cases pin holes were formed into the bores in the aft end of the peripheral elements with rivers of corrosion down stream from the external end of these pin holes. It is important not only that the interstitial leakage be extremely low, but also that the interstitial pressures be somewhat higher than the bore pressure in 


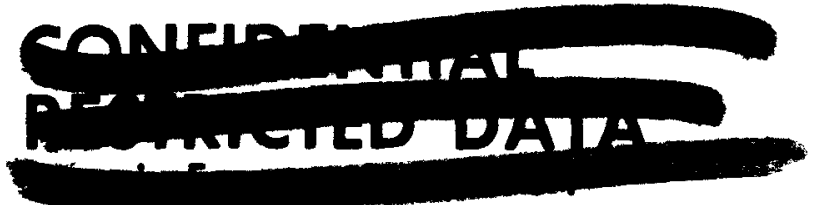

adjacent fuel elements. This necessity again points up the importance of good dimensional control and good bundling. To obtain good hot end bundling, it will be necessary to prevent the drop off in temperature of the fuel elements at the exhaust end. This can be accomplished by increasing the length of non-fuel tips or the length of the support blocks to increase the neutron level at the exhaust end.

In NRX-A the interstitial flow has been estimated as $0.016 \mathrm{lb} / \mathrm{sec}$ or $57.6 \mathrm{lb} / \mathrm{hr}$. This includes some addition to the axial flow due to radial inflow. With a design having a tight peripheral region, this flow would be reduced somewhat. Using the above flow, and the same ratio of carbon to hydrogen at the exit as was used in the peripheral analysis, shows a carbon loss of 38 to 40 lbs. from the interior of the core. This loss may not be excessive if the design is such that the corrosion occurs at planned locations (sacrificial carbon).

Central Element and Instrument Corrosion:

In the central unfueled element there is a leakage flow of hydrogen through the region occupied by the pyro graphite insulating sleeves. This results in corrosion of the bore of the unfueled element. This corrosion can be prevented by coating the bore. On larger runs, corrosion of the hot surface of the pyro graphite sleeves will probably show up. Coating of pyro is difficult. A better solution to this problem would be to eliminate the hydrogen flow. Studies to this end are being started.

In-core instrumentation from the standpoint of instrumentation itself, and its effect on corrosion in the core, has turned out to be a serious problem. Each type of instrument should be shown to be adequate by a complete series of component tests. In-core instrument installation should be a major part of the reactor design study. 

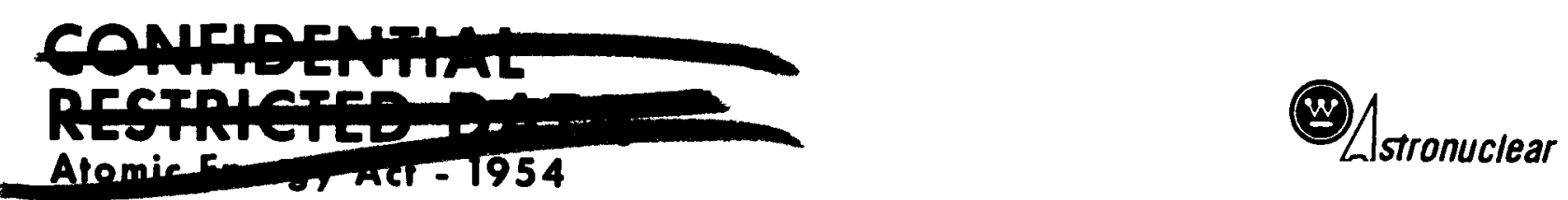

WANL-TME-1068

Possible hydrogen flow paths must be reduced or eliminated. Each type of installation should be thoroughly tested and demonstrated by component tests simulating in-core conditions.

Interfaces:

The interfaces between the reactor and the pressure vessel, and nozzle should be simplified. We are presently examining the NRX-A design to make sure that there is not an interference between the nozzle plenum I. D. and the envelope of the reactor support blocks. The possibility of an interference between the support blocks and the nozzle should be removed either by moving the corenozzle sealing surface away from the support block region, or by increasing the clearance between parts to a point where interference is of no concern.

The instrumentation stocks should be equipped with plug-in connectors to speed up and simplify the wiring in Nevada and to make disconnecting of a hot reactor easy. Seals for these stocks and for the control drive tubes should be selected, which are rugged and insensitive to mechanical loading or temperature of these parts. Their adequacy should be demonstrated by component tests.

Instrumentation to measure the exhaust plenum conditions, such as pressure and temperatures, should be designed so the sensors are installed with the reactor and the lines to the sensors should be brought out through the control stocks.

Fuel Element Support Block Interface:

In both hot reactor runs and in the component test programs, it has been demonstrated that the coating on the support blocks and on the fuel element hot ends do fuse together and that the coating may break away from the coated surfaces. It is not known whether this is a serious problem for long runs. Component tests are underway which will determine the seriousness of the problem and should lead to $-6-$

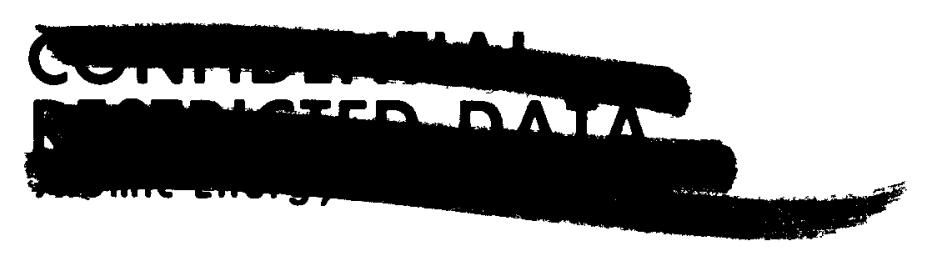


solutions. Suggested solutions have been to provide a non-welding material between the support blocks and the fuel elements. Such a material has not yet been identified and tested. LASL is attempting to eliminate the support block itself by combining it with a non-fueled tip on the fuel element. WANL has sketched designs incorporating the support block with the central non-fueled element. The fueled elements are cemented to the central element at the exhaust end.

Growth Capabilities:

Mission studies have shown the need for a larger nuclear engine or possibly a family of engines. Any redesign of the NERVA reactor should take into account these growth needs. This growth need would be in increased power density capability, increased I $S P^{\prime}$ and increased power level. To increase the power density, it will be necessary to re-examine the fuel geometry and the operating pressure levels. The NERVA II studies show that increasing the fuel element bores to $0.115 \mathrm{in}$. from the $0.098 \mathrm{in}$. of NRX-A would permit a propellant flow increase at the same pressure drop of about $50 \%$ with a corresponding increase in the power per unit volume of the reactor. However, this would cause an increase of the void fraction from 0.29 to 0.40 . This would result in an intolerable increase in the fuel loading per element in a reactor of the NRX-A size. Some more modest increases in bores can probably be permitted. The flow can also be increased if the propellant density is increased by raising the nozzle chamber pressure, or if the pressure drop across the core is increased.

By eliminating the by-pass flow in the core peripheral region, the fuel element exit gas temperature is reduced for a given chamber temperature. This reduction in temperature can be taken advantage of to reduce the hot spot fuel element temperature or to increase the $\mathrm{I}_{\mathrm{SP}}$. 
The NERVA II studies have shown that the basic NERVA design can be increased to effective core diameters of 55 to $60 \mathrm{in.}$ from the NRX A-2 diameter of $35 \mathrm{in.} \mathrm{by} \mathrm{using} \mathrm{more} \mathrm{and} \mathrm{larger} \mathrm{control} \mathrm{drums.} \mathrm{Test} \mathrm{Cell} \mathrm{A}$ at NRDS cannot be simply modified to test these larger reactors. Therefore, the NRX-A7 to Al0 series should be essentially the same size as NRX-A.

Simplified Hot Disassembly:

The NRX-A2 problems with the cluster nuts in the core support plate and the necessity for sawing the inner barrel apart to dismantel the core emphasises the need for simplifying hot disassembly in any reactor design. The preliminary studies have arrived at a conceptual design which is considerably easier to disassemble. For example: all of the lateral support springs can be released by removing the screw plugs which hold the lateral springs in place. These plugs are on the periphery of the beryllium reflector. They are large and have large wrench sockets for easy removal. The top support plate is bolted to the reflector assembly by a single ring of bolts. These can be designed for easy removal by remote manipulators. By releasing the springs and removing these bolts, the core assembly can be lifted vertically, leaving the complete outer reflector assembly with its seal rings and control drums in-tact.

Component Test Program:

Since the proposed design is different from the present NRX reactor in a number of areas, it will be necessary to redirect the component test program to obtain data to support the design. Most of the major test facilities and fixtures for this redirected effort are presently available. The interstitial and peripheral pressures, and pressure distribution under cold conditions can be studied 
by means of the plugged core test facility. These tests will require a number of modifications or rebuilds of this facility. For example: it would be necessary to eliminate the push pins and their associated leakage, and eliminate the grooves in the seal sectors to reduce the axial leakage. Another reassembly might place a mylar or similar film barrier around the core to separate the interstitial leakage from the seal leakage. Additional leakage data might be obtained from the core mockup in the Engineering Mechanics Laboratory. Hot core geometries both in the peripheral region and the interstitial region can be mocked up and tested in the single cluster A-10 fixture and with some modifications of the 7 cluster A-11 fixture. Tests to obtain data on corrosion and carbon deposition in single narrow channels to develop an understanding of the corrosion mechanism are being made in the HHT6 rig. Additional tests can be made in either the A-2 furnace at Large or the duplicate A-2 furnace at Waltz Mills. The A-2 furnace is being used to test in-core sensors and the designs for their core installation. Mechanical tests and other tests at temperatures, which do not require flowing hydrogen can be performed in the 6 in. diameter $\times 10$ in. long and 6 in. diameter $\times 54$ in. long furnaces in the Engineering Mechanics Laboratory.

\section{SCHEDULES:}

An examination of schedules show the importance of making an early decision of the direction the $A-7$ to $A-10$ reactor design should take. For example: if the suggested design is considered seriously as a contender, orders for beryllium pieces, which would be large enough to accommodate the suggested design, should be placed now. A firm size cannot 
be specified for the beryllium at the present time. However, at a comparative small cost, pieces large enough to accommodate any foreseeable design requirements, can be procurred. Design modifications of the beryllium may be required to permit other suppliers to manufacture these pieces. This reactor would differ enough from the NRX-Al through A-6 series that a new critical assembly would be needed. The beryllium for this critical assembly should be procurred as soon as possible. 

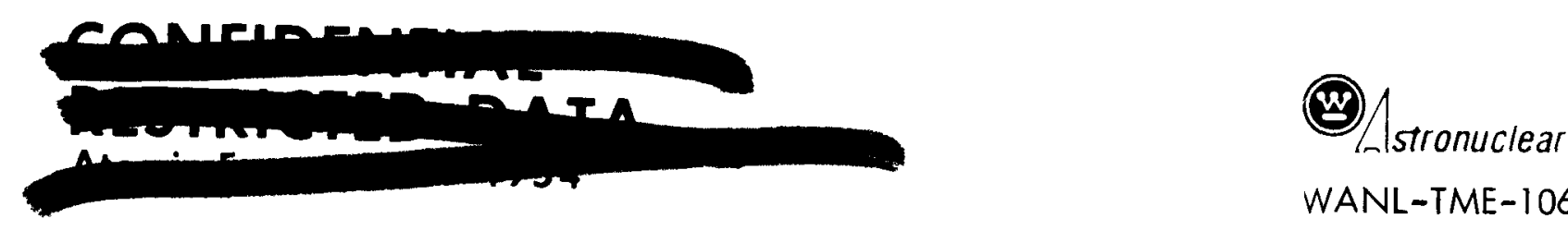

WANL-TME- 1068

\section{DESCRIPTION OF THE PROPOSED DESIGN:}

Figure 1 shows a preliminary study of a reactor which has the potential of achieving the objectives discussed. Most of the features are the same as NRX-A. The major change shows the inner reflector graphite barrel replaced by a series of fixed graphite rings and graphite seal sectors.

Figure 2 shows a cross section through the beryllium outer reflector and this system of rings. The fixed rings could be either made up of sectors or one piece of graphite. They are held in grooves machined in the inner surface of the beryllium reflector. This machining would be accomplished by assemblying the sectors, dowelling them carefully to the top and bottom support rings, and to each other, and machining the grooves in the assembled reflector. The fixed graphite rings would be a compression fit in these machined grooves. Tension bands around the outside of the reflector would provide the compression load. The seal sectors would seal against these rings. Pyro-graphite faces on the fixed rings would reduce their temperature and the heat input from the core to these colder graphite parts.

Figure 3 shows details of the arrangement at the cold end of the reactor. The barrel hold drun springs with their associated support rings have been eliminated. The finger seal between the core and the support plate has been replaced by a $W$ seal between the core support plate and the $Z$ ring. This $W$ seal assured that coolant from the reflector will be directed through the ring supporting the core support plate.

Figure 4 shows the suggested arrangement of a seal at the exhaust end between the reactor and the nozzle. It will be necessary to provide the capability of considerable movement in the seal to accommodate tolerance build up and the difference in expansion between the core parts, the nozzle and reactor vessel.

Figure 5 shows a cross section through the core, reflector, and interface regions. It illustrates the arrangement of springs which activate the seal segments. These springs are in holes through the beryllium sectors. They are made of coilled flat wire and are 


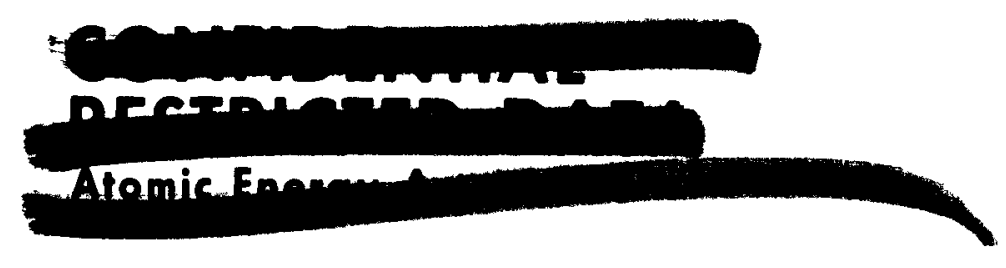

(v) Astronuclear

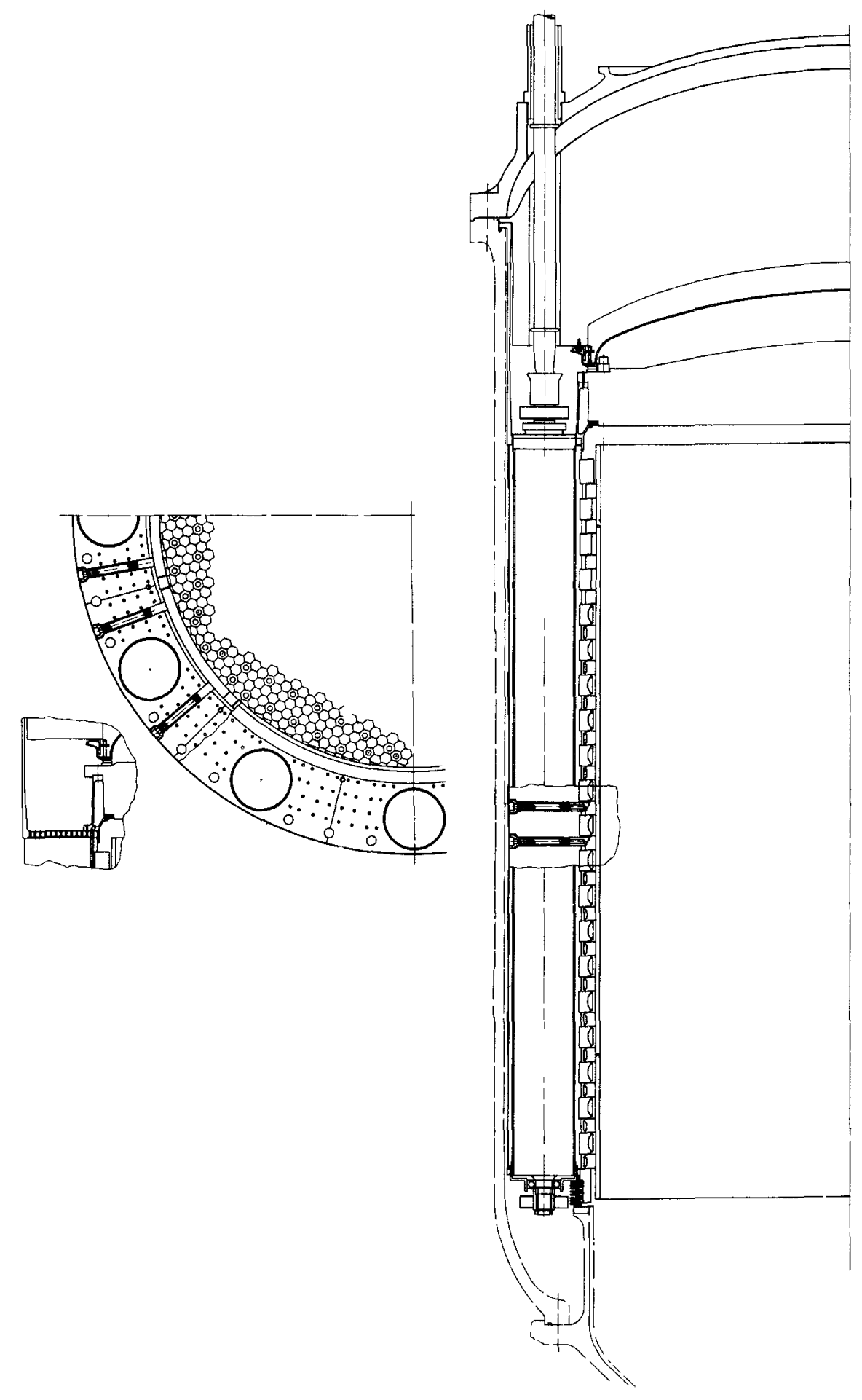

Figure 1

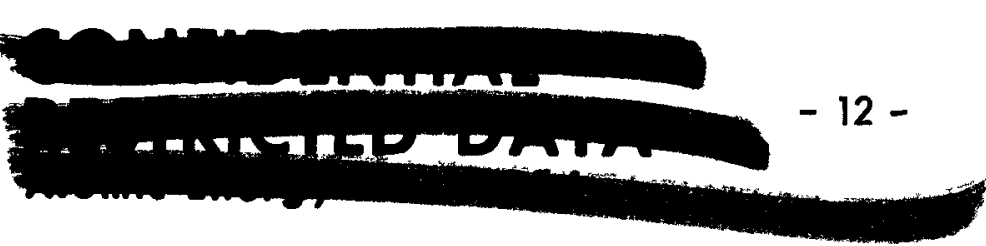




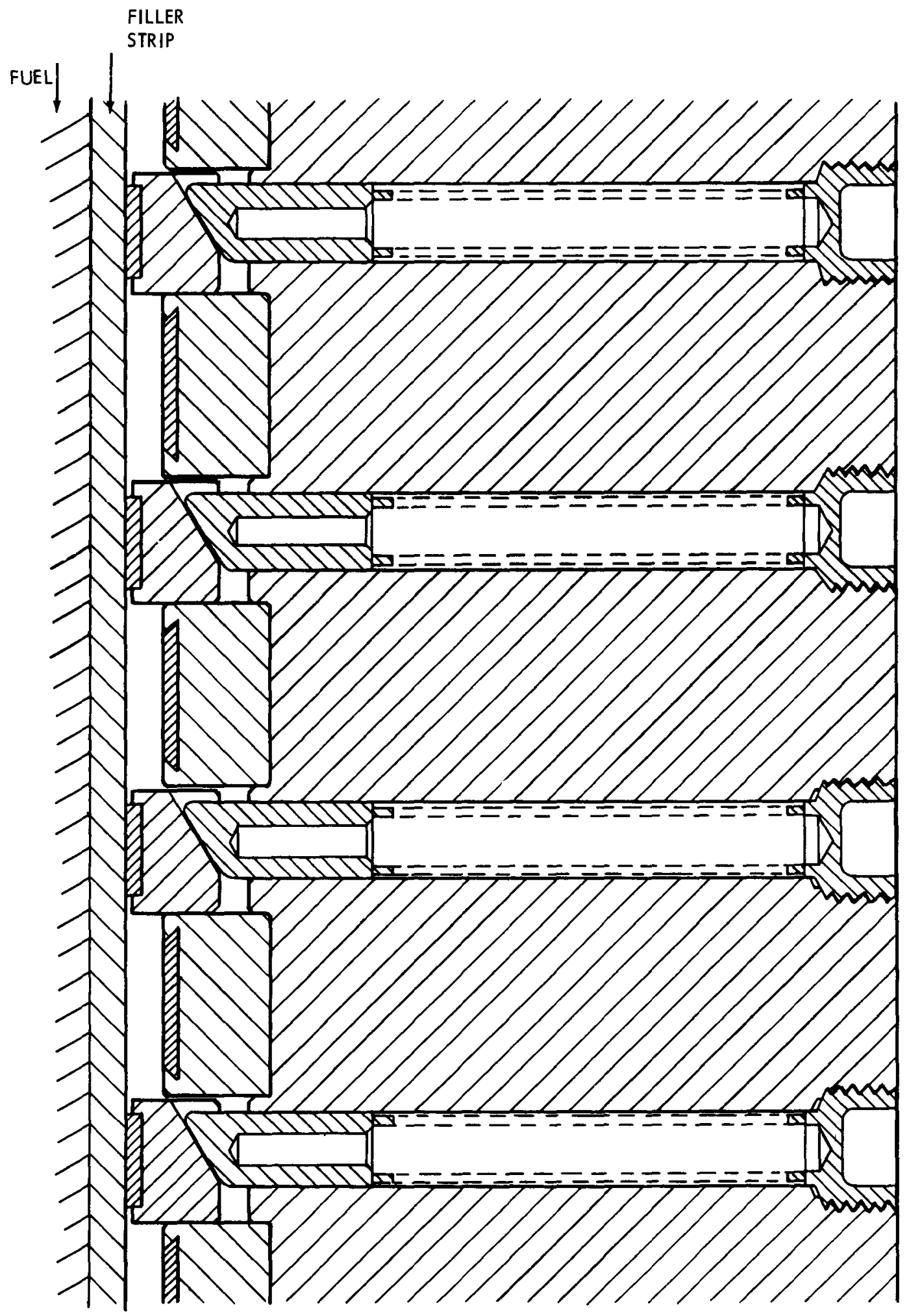

Figure 2

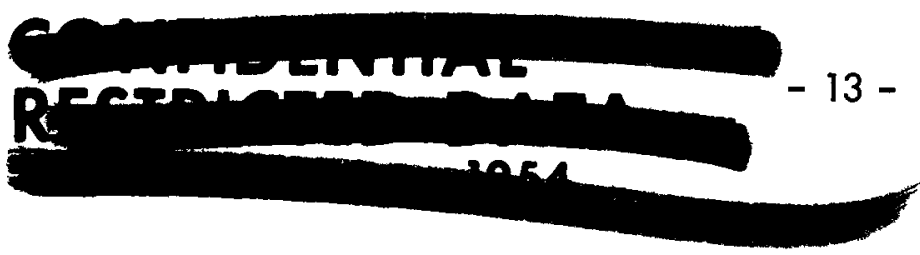



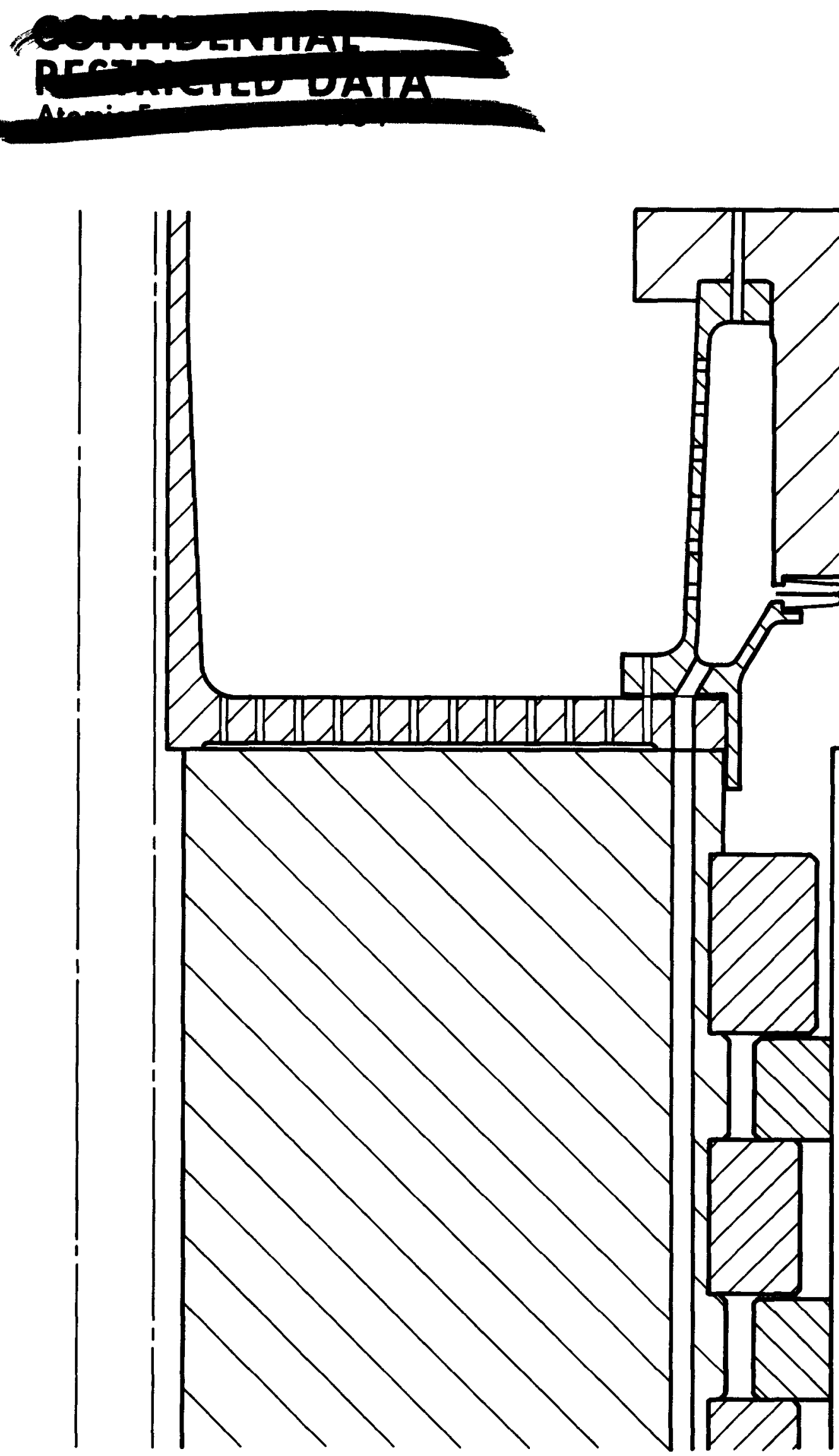

Figure 3

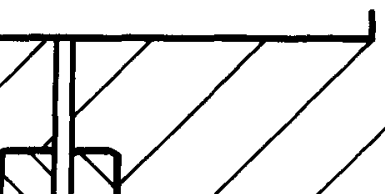




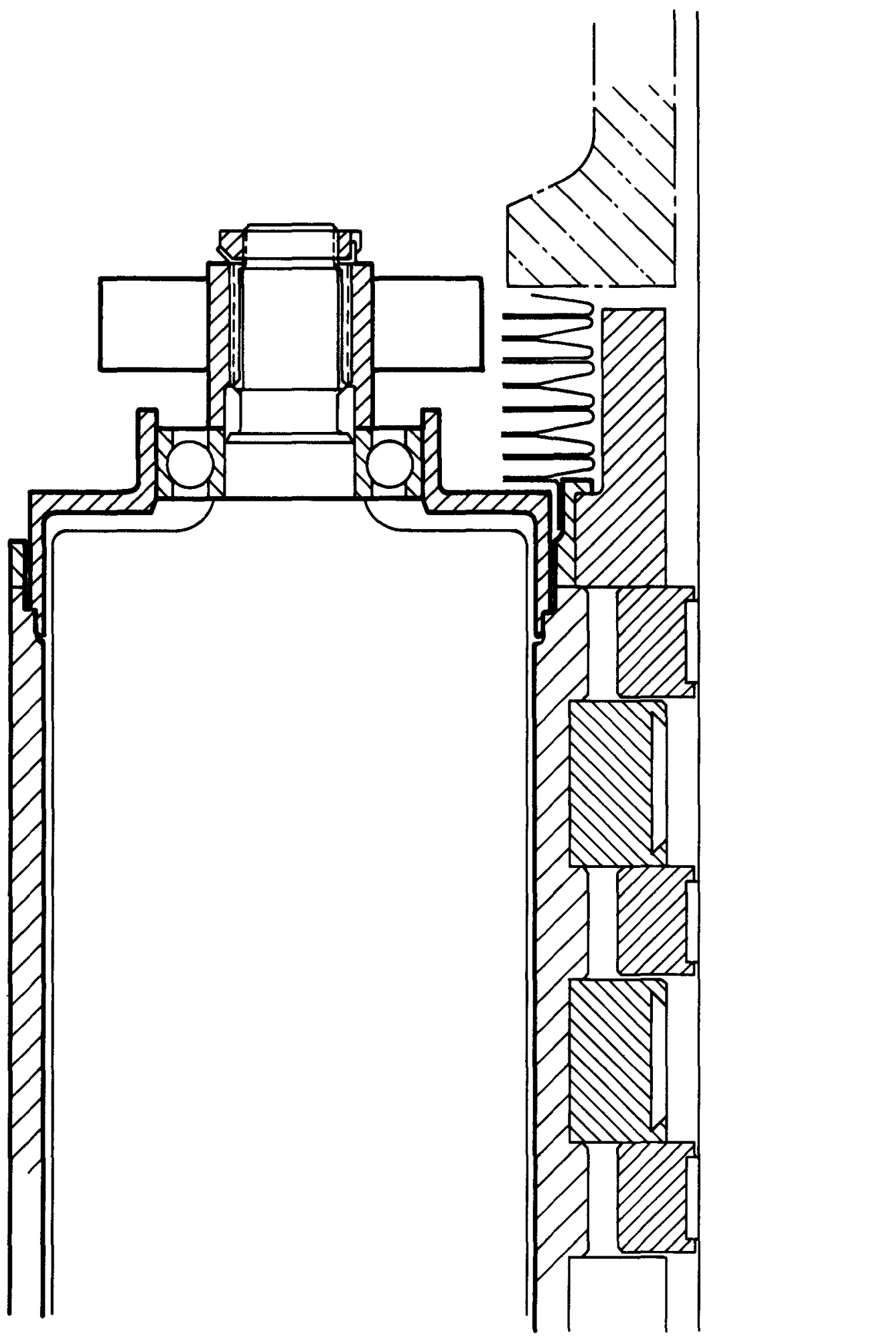

Figure 4

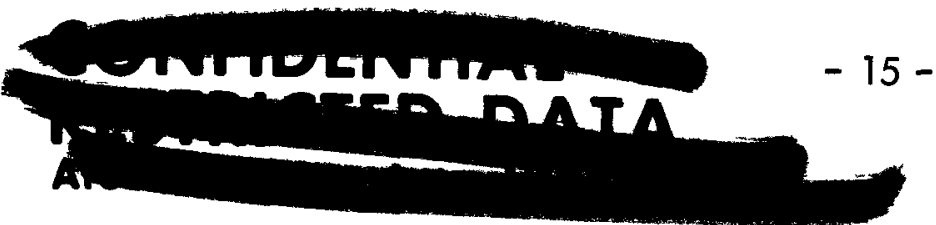




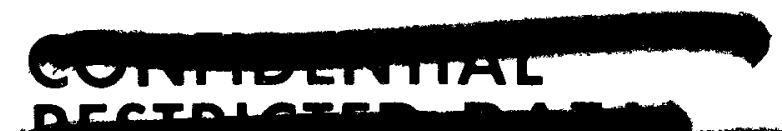

(4)
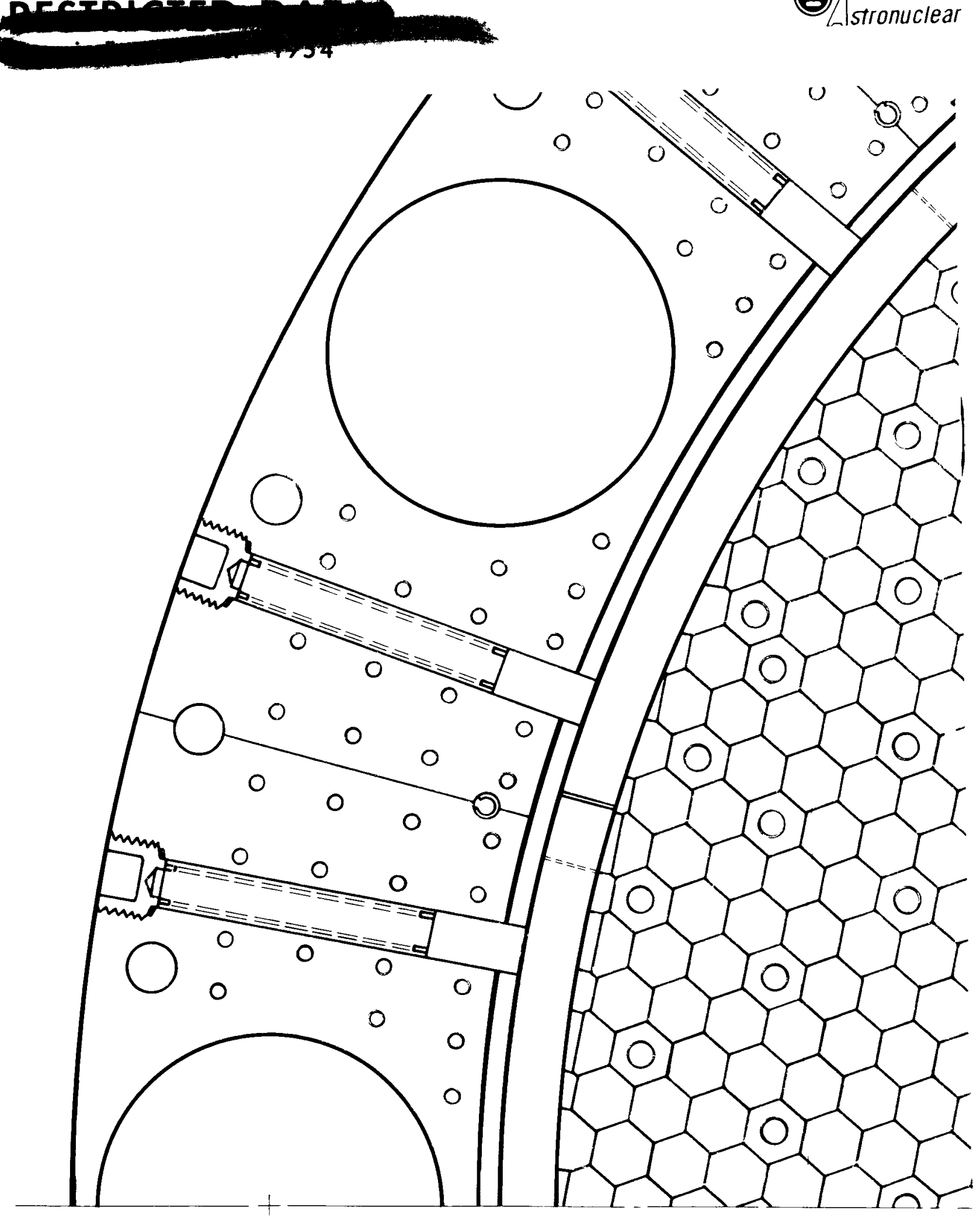

Figure 5

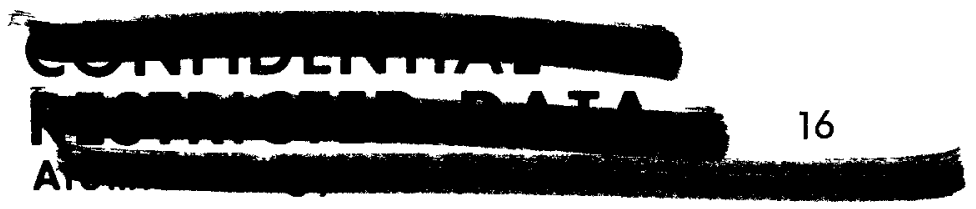


cooled by conduction to the beryllium. They would be completely sealed by the screw plug at the outer end. Leakage into the core peripheral area through the spring push pins would be zero.

The elimination of the graphite barrel resulted in the following changes in reactor geometry:

The mean beryllium reflector thickness increased from $4.619 \mathrm{in}$. in NRX-A to $5.185 \mathrm{in.}$ The control drum diameter increased from 4.108 in. to $4.338 \mathrm{in}$. The radius of the drum center line was reduced from $22.375 \mathrm{in}$.

to $22.050 \mathrm{in}$. About 120 additional fuel elements were added to the core. The equivalent graphite reflector thickness was reduced from 2.31 in to $1.51 \mathrm{in.}$

Figure 6 shows the core periphery together with the arrangement of uncooled filler strips.

Figure 7 shows a preliminary estimate of the temperature profiles through the peripheral areas in the mid core position. The upper graph shows the profile through the fixed spacer ring which is in the grooves in the beryllium. At this station, the fuel surface temperature would be about $3300^{\circ} \mathrm{R}$. There would be a temperature drop in the gap and the pyro facing to the spacer ring temperature of $2000^{\circ} \mathrm{R}$. There is an additional drop to about $1000^{\circ}$ at the opposite face. There would be a small contact drop between the graphite ring and the beryllium. The gradient in the beryllium would be low and should not be troublesome. The lower graph shows the temperatures through a seal segment. This temperature difference is small. Therefore, the pyro-tile can be eliminated and the seal segments can be placed directly in contact with the filler strips. Since there is a flow of heat from the seal segment to the beryllium, there will be some drop in temperature through the segment and a large drop in the gas gap between the segment and beryllium. Again the temperature gradients in the beryllium would be quite low because of the limited heat input

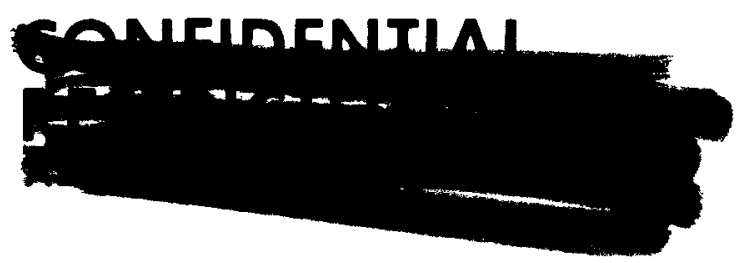




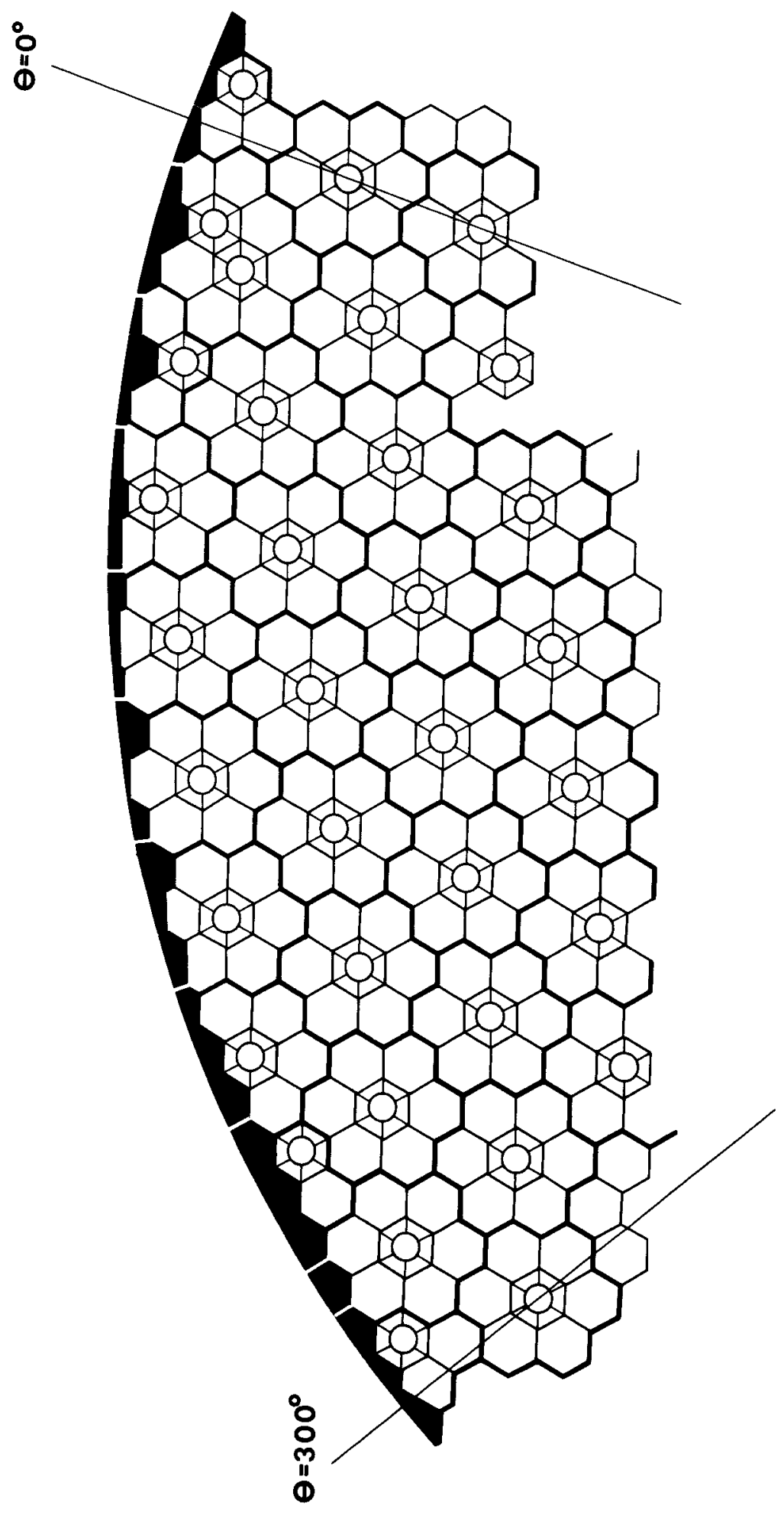

Figure 6

CONIRERTIAI

- 18 -

(4) Astronuclear 

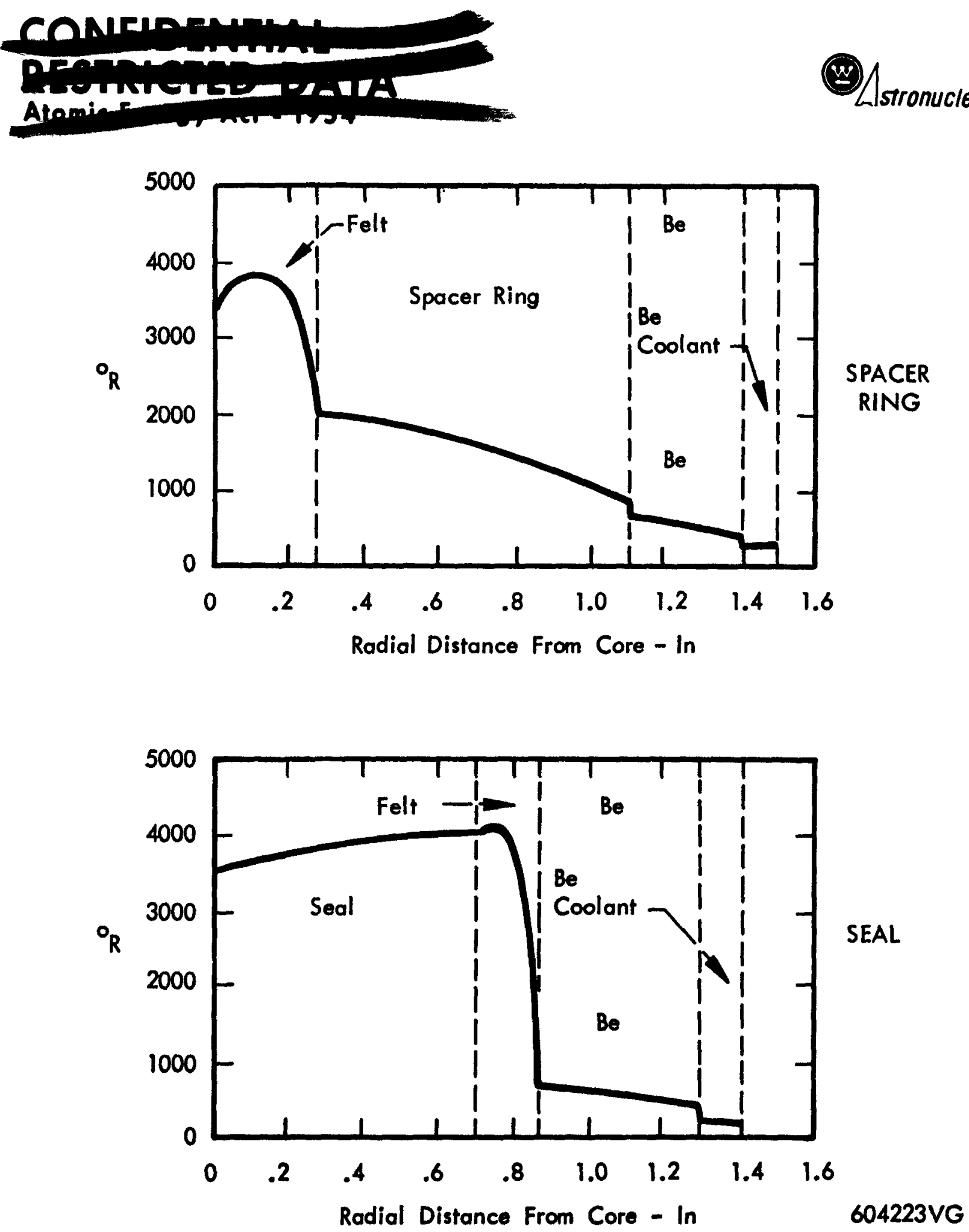

ESTIMATED TEMPERATURE LEVELS STATION 26

Figure 7

\section{CenieInENITIAI}




\section{(n)}

through the gas gap. An examination of these graphs suggests modifications which can be made to improve the corrosion pattern. Since the spacer rings would be considerably lower in temperature than the other graphite parts in the peripheral area, there would be a deposition of pyro-carbon on the se rings. The seal sectors show their highest temperature on the filler strip side and they would therefore corrode at this point. Both of these situations can be corrected by the judicious use of pyro-carbon or other insulating material. A later figure illustrates such a solution.

In addition it would be possible to eliminate the corrosion problem by bathing the peripheral area in helium. Figure 8 is an arrangement for accomplishing this. A core band similar to NRX-A2 would be provided at the cold end of the core. This band would be cooled by a by-pass flow of hydrogen from the beryllium reflector. The hydrogen would then be ducted up to cool the core support plate ring. Somewhat farther aft, helium would be brought in to the seal area through ducts in the beryllium reflector. This helium would be at a slightly higher pressure than the hydrogen which cools the core band, thus making sure that hydrogen is barred from the hot peripheral areas. Some helium would flow up and mix with the hydrogen cooling the core band. The remainder would flow down and provide a non-corrosive blanket. This scheme would require the addition of a helium supply system consisting of a pressurized helium bottle, a pressure regulator valve to regular the helium pressure with respect to the reflector exit pressure, and a shut off valve. This system does add some to the complexity of the engine system; however, it does provide an effective means of preventing peripheral corrosion.

Figure 9 shows a method of using graphite cloth or felt to modify the temperature profiles in the fixed graphite rings and in the seal sectors to control the corrosion pattern. Felt would be placed on the inner surface of the fixed rings which would shield this cooler graphite from the hot hydrogen. This felt would also act as a source of graphite, and in addition make sure that the interface between the filler strips and seal sectors was

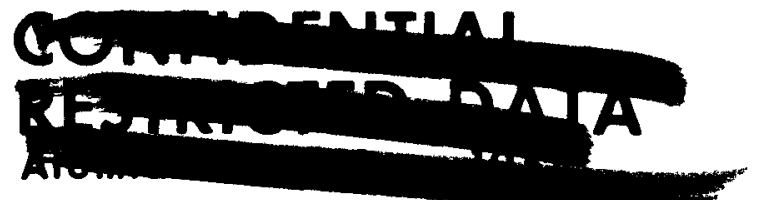




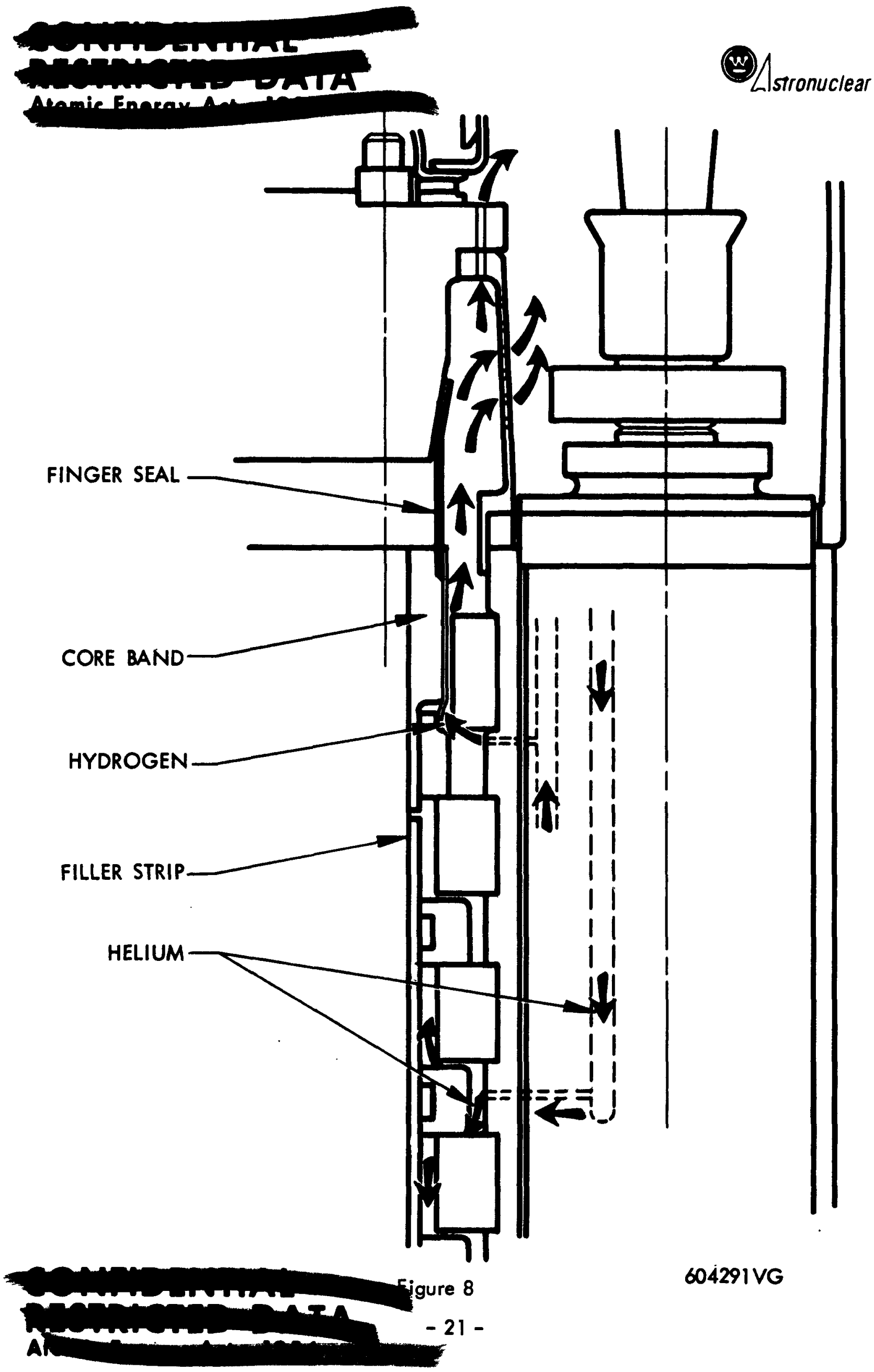



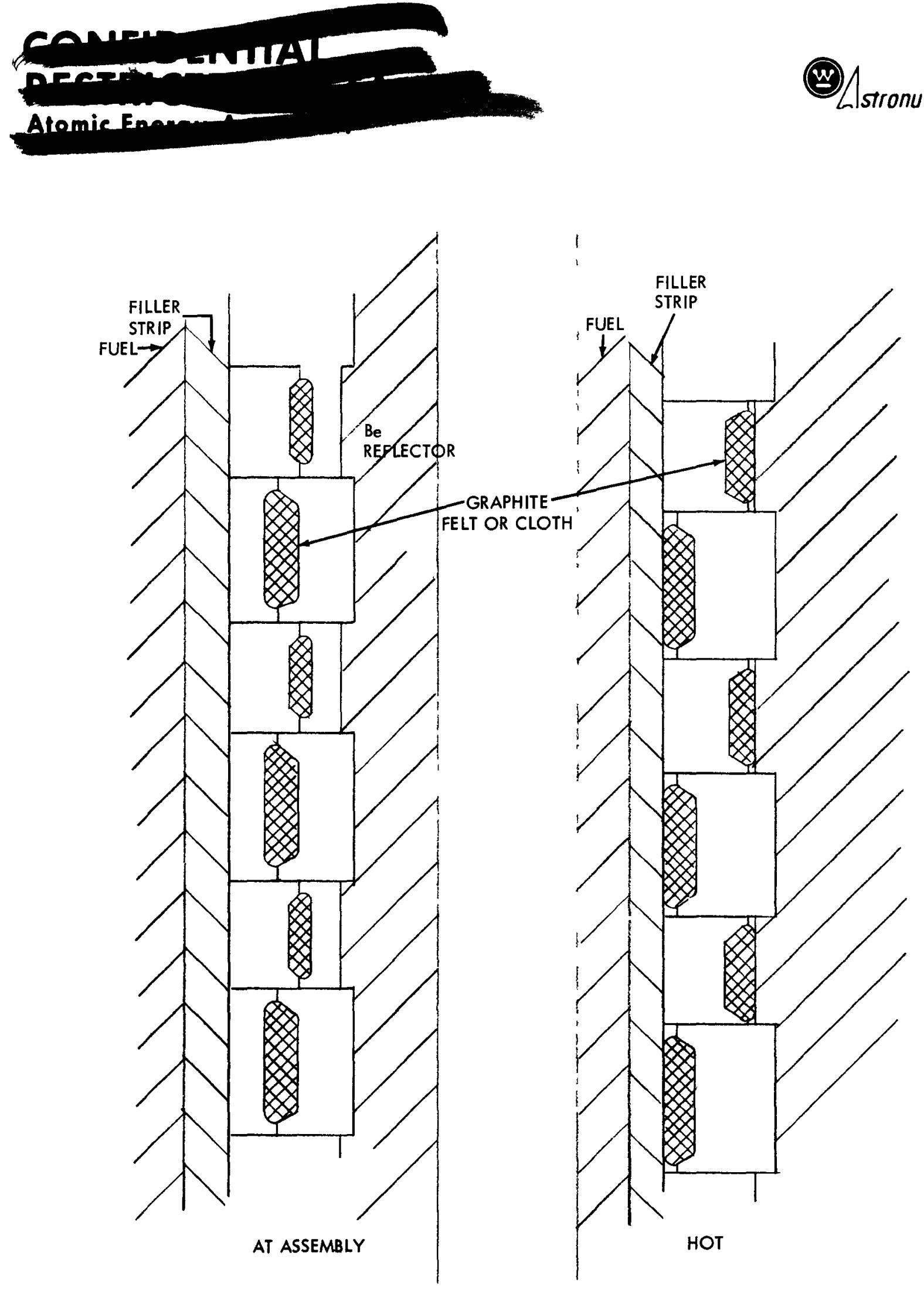

Figure 9

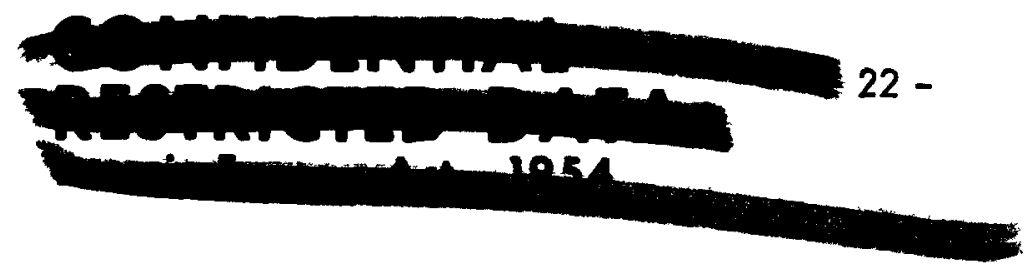


at a lower temperature then the body of the seal sectors and thus prevent corrosion at the interface.

The graphs of figure 10 illustrate the approximate temperature patterns which would be expected with this arrangement. The addition of the graphite felt to the core side of the spacer ring would isolate the cold surface of this ring from the hot hydrogen. Pyro-carbon will not be deposited on this surface. It would also reduce the radiant heat load into this ring and therefore, the heat which must be transmitted to the beryllium. The felt on the outer radius of the seal segments would reduce the heat radiated from this surface to the beryllium. This would move the high temperature part of this part from the sealing surface to the outer surface. Corrosion would not occur on the sealing surfaces or the fuel surface. As a mater of fact, the highest temperatures would occur in the felt itself. Its sacrificial corrosion would protect the other parts. 